\title{
Hyperoxia increases the uptake of 5-fluorouracil in mammary tumors independently of changes in interstitial fluid pressure and tumor stroma
}

\author{
Ingrid Moen ${ }^{1,2}$, Karl J Tronstad ${ }^{1}$, Odd Kolmannskog1, Gerd S Salvesen ${ }^{1}$, \\ Rolf K Reed ${ }^{1}$ and Linda EB Stuhr*1
}

Address: ${ }^{1}$ Department of Biomedicine, University of Bergen, Bergen, Norway and ${ }^{2}$ Heart and Circulatory Research Group, Haukeland University Hospital, Bergen, Norway

Email: Ingrid Moen - ingrid.moen@biomed.uib.no; Karl J Tronstad - karl.tronstad@biomed.uib.no;

Odd Kolmannskog - odd.kolmannskog@helse-bergen.no; Gerd S Salvesen - gerd.salvesen@biomed.uib.no;

Rolf K Reed - rolf.reed@biomed.uib.no; Linda EB Stuhr* - linda.stuhr@biomed.uib.no

* Corresponding author

Published: 17 December 2009

BMC Cancer 2009, 9:446 doi:10.1 186/147|-2407-9-446
Received: 18 June 2009

Accepted: 17 December 2009

This article is available from: http://www.biomedcentral.com/I47I-2407/9/446

(c) 2009 Moen et al; licensee BioMed Central Ltd.

This is an Open Access article distributed under the terms of the Creative Commons Attribution License (http://creativecommons.org/licenses/by/2.0), which permits unrestricted use, distribution, and reproduction in any medium, provided the original work is properly cited.

\begin{abstract}
Background: Hypoxia is associated with increased resistance to chemo- and radiation-therapy. Hyperoxic treatment (hyperbaric oxygen) has previously been shown to potentiate the effect of some forms of chemotherapy, and this has been ascribed to enhanced cytotoxicity or neovascularisation. The aim of this study was to elucidate whether hyperoxia also enhances any actual uptake of 5FU (5-fluorouracil) into the tumor tissue and if this can be explained by changes in the interstitium and extracellular matrix.
\end{abstract}

Methods: One group of tumor bearing rats was exposed to repeated hyperbaric oxygen (HBO) treatment ( $2 \mathrm{bar}, \mathrm{pO}_{2}=2$ bar, 4 exposures à $90 \mathrm{~min}$ ), whereas one group was exposed to one single identical $\mathrm{HBO}$ treatment. Animals housed under normal atmosphere $\left(\mathrm{I}\right.$ bar, $\left.\mathrm{pO}_{2}=0.2 \mathrm{bar}\right)$ served as controls. Three doses of $5 \mathrm{FU}$ were tested for dose response. Uptake of $\left[{ }^{3} \mathrm{H}\right]-5 \mathrm{FU}$ in the tumor was assessed, with special reference to factors that might have contributed, such as interstitial fluid pressure $\left(P_{\text {if }}\right)$, collagen content, oxygen stress (measured as malondialdehyd levels), lymphatics and transcapillary transport in the tumors.

Results: The uptake of the cytostatic agent increases immediately after a single HBO treatment (more than 50\%), but not 24 hours after the last repeated HBO treatment. Thus, the uptake is most likely related to the transient increase in oxygenation in the tumor tissue. Factors like tumor $P_{\text {if }}$ and collagen content, which decreased significantly in the tumor interstitium after repeated HBO treatment, was without effect on the drug uptake.

Conclusion: We showed that hyperoxia increases the uptake of $\left[{ }^{3} \mathrm{H}\right]-5 \mathrm{FU}$ in DMBA-induced mammary tumors per se, independently of changes in $P_{\text {if }}$, oxygen stress, collagen fibril density, or transendothelial transport alone. The mechanism by which such an uptake occur is still not elucidated, but it is clearly stimulated by elevated $\mathrm{pO}_{2}$. 


\section{Background}

A tumor is comprised of cancer cells as well as stromal cells (fibroblasts, immune cells) that are embedded in an extracellular matrix (ECM) and nourished by vasculature. Because of irregular and tortuous tumor blood vessels with impaired blood flow and high proliferation rate, tumors have large hypoxic areas, especially in the central parts. It is now widely accepted that hypoxia induces tumor growth and enhances both radiation- and chemoresistance of cancer cells [1].

Inefficiency of chemotherapy can partly be explained by development of multidrug resistance to different chemotherapeutic agents. However, the causes of hypoxia-mediated resistance are multifactorial. Some chemotherapeutic drugs require oxygen to generate free oxygen radicals that in turn induce cytotoxicity. Genetic and proteomic changes may have substantial effect, by altering proliferation kinetics, cell cycle position, inhibiting apoptosis and regulate angiogenesis and cellular metabolism [2]. However, drug resistance can also be caused by the inefficient transport of the anticancer drug into the tumor tissue. Solid tumors have a pathologically increased interstitial fluid pressure $\left(\mathrm{P}_{\mathrm{if}}\right)$ and a dense ECM that make transport of chemotherapeutic agents difficult [3-7]. Increased $P_{\text {if }}$ leads to decreased transcapillary transport, and thereby hinders efficient uptake of chemotherapy [8], while the fibrotic nature of the dense ECM in solid tumors have been shown to impede transport of molecules in the tumor interstitium, and thereby decrease the effect of cytostatic drugs [9-11]. Since $P_{\text {if }}$ can be lowered and the structure of the tumor interstitium can be altered, this could have the potential to enhance the efficiency of drugbased treatment of solid malignancies.

As hypoxia reduces the response of chemotherapeutic agents, we aimed to study the effect of enhanced oxygenation on drug-uptake in mammary tumors, by using hyperbaric oxygen (HBO). HBO increases oxygen tension and oxygen delivery to tissues independent of haemoglobin. This $\mathrm{pO}_{2}$ elevation has been shown to last for up to 60 min post HBO treatment [12]. Because of this, HBO has previously been used to enhance the $\mathrm{pO}_{2}$ in hypoxic tumor tissue, to potentiate the effect of radio- and phototherapy in both clinical and preclinical trials and also the effect of some forms of chemotherapy like doxorubicin, alkylating agents and 5FU [13-16]. This effect has been ascribed as increased cytotoxicity of the tumor cells to the chemotherapeutic drug in vitro $[16,17]$ and enhanced neovascularisation in vivo [18]. However, recent studies have shown reduced vascularisation after $\mathrm{HBO}$ treatment in vivo [19-21].

Therefore, the aim of the present study was to study if there is an effect of either a single (1) or repeated (4) treat- ments (each $90 \mathrm{~min}$ ) of 2 bar pure oxygen on the uptake of radioactively labelled 5FU in the tumor tissue per se, and whether this is related to elevated $\mathrm{pO}_{2}$ and microenvironmental factors like $\mathrm{P}_{\mathrm{if}}$, collagen fibrils, transcapillary transport and oxygen stress. We would then be able to conclude that the HBO enhancement of chemotherapeutic effects, previously shown in the literature, is not only due to an enhanced sensitisation of the tumor cells.

\section{Methods \\ Animals and tumor model}

Female Sprague-Dawley rats were used. Mammary tumors (adenocarcinomas) were induced by dimetyl- $\alpha$-benzantracene (DMBA) dissolved in olive oil and given to the rat by gavage at the age of 7 weeks at a dose of $16 \mathrm{mg}$ (Møllegård, Denmark). The experiments were performed when the rats were 13-15 weeks old, having reached a bodyweight of approximately $250 \mathrm{~g}$ and developed one to three tumors along the mammary crest. Thus, $\mathrm{n}$ is equal to number of tumors, not the number of rats in these experiments. This was done to minimize the number of animals used. As tumors are very heterogenous, this was not considered a problem. We did not perform a power analysis prior to the experiments. The number of animals in each group is determined based on previous experience with rat experiments. However, this is always a general compromise between experimental accuracy and at the same time keeping the number of animals as low as possible. The previous variance in animal experiments has resulted in the minimum number of animals to $n=5$. The animals were randomly allocated to the treatments groups, and none were excluded from the treatment procedure. Malondialdehyde and hydoxyproline experiments were performed blinded. As the main investigator performed both the HBO treatment and the rest of the follow-up experiments, blinding was difficult to accomplish. All the experiments were performed in accordance with recommendations of the Norwegian State Commission for Laboratory Animals and were approved by the local ethical committee.

\section{Hyperbaric hyperbaric chamber}

A $30 \mathrm{~L}$ pressure chamber with an inner diameter of $25 \mathrm{~cm}$, and an inner length of $65 \mathrm{~cm}$ was used. The chamber was supplied with pure $\mathrm{O}_{2}$, and the oxygen concentration (\%) was monitored continuously by an oxygen meter (NUI, Bergen, Norway). After reaching $100 \% \mathrm{O}_{2}$ within approximately $10 \mathrm{~min}$, the pressure was raised over a period of approximately $3 \mathrm{~min}$ to 2 bar. The 2 bar pure oxygen atmosphere was maintained for a period of $90 \mathrm{~min}$. To maintain $>97 \% \mathrm{O}_{2}$ atmosphere at all times, the chamber was flushed with pure oxygen for 3-5 min every 10-30 min depending on the number of animals in the chamber. The rats were then decompressed over a period of $10 \mathrm{~min}$. 


\section{Experimental groups and treatment design}

The different experimental groups and their treatment details are given in Table 1 . The repeated HBO treated rats were exposed to HBO on day 1, 4, 7 and 10, and the follow-up experiments were performed on day 11 . The choice of this treatment protocol is due to a previous study [20], showing that 4 HBO treatments gave maximal growth-inhibitory effect. The single $\mathrm{HBO}$ treated group was only exposed to HBO on day 1 and measurements performed immediately after the exposure.

\section{Dose response of $\mathbf{5 F U}$}

We tested 3 different doses of 5FU. Original dose $(1.5 \mathrm{mg} /$ $\mathrm{kg}), 1 / 3(0.5 \mathrm{mg} / \mathrm{kg})$ dose and $3 \times(4.5 \mathrm{mg} / \mathrm{kg})$ dose $5 \mathrm{FU}$ was injected intraperitonally and tumor size was measured by a calliper on day 1, 4, 7 and 11, and estimated according to the formula: $V=\pi / 6\left(a^{2} \cdot b\right)$, where ' $a$ ' denotes the shortest transversal diameter and ' $b$ ' the longest transversal diameter. Growth was calculated as growth change compared to day $1(100 \%)$.

\section{Microdialysis}

To determine the uptake of radioactively labelled 5FU ([3 $\left.\left.{ }^{3}\right]-5 F U\right)$ (Nycomed Amersham, Buckinghamshire, UK) into the tumor tissue, microdialysis technique [22] was used, as modified in our laboratory [23]. After anaesthesia, the femoral vein was cannulated for injection of $\left[{ }^{3} \mathrm{H}\right]-$ 5FU. One microdialysis probe (CMA/20, Microdialysis $\mathrm{AB}$, Stockholm, Sweden) was placed in the jugular vein and one in the tumor. Both probes were connected to a pump (CMA-100, Microdialysis AB, Stockholm, Sweden) and the catheters were perfused with saline at a rate of 1 $\mu \mathrm{l} / \mathrm{min}$. The catheter and probes were left to stabilize and equilibrate for $60 \mathrm{~min}$ before sampling of dialysate. Sampling of dialysate from both tumor and plasma started immediately after injection of $0.2 \mathrm{ml} 0.37 \mathrm{Mbq}\left[{ }^{3} \mathrm{H}\right]-5 \mathrm{FU}$ and fractions were collected every $10 \mathrm{~min}$ for a total of 70 min. The area under the curve (AUC) for the plasma and tumor was calculated as the product of counts per $10 \mathrm{~min}$ (cpm) for a total measurement period of $70 \mathrm{~min}$. Transport of $\left[{ }^{3} \mathrm{H}\right]-5 \mathrm{FU}$ was expressed as AUC tumor divided by AUC plasma.

An additional, single HBO exposure group was performed to elucidate if the generally known enhanced effect of cytostatic agents in combination with $\mathrm{HBO}$ is due to the high $\mathrm{pO}_{2}$ during and immediately after HBO exposure.
The rats were therefore operated before the single $90 \mathrm{~min}$ HBO exposure, and left to stabilize for $15 \mathrm{~min}$ post exposure. $0.2 \mathrm{ml} 0.37 \mathrm{MBq}\left[{ }^{3} \mathrm{H}\right]-5 \mathrm{FU}$ was injected into the femoral catheter, and dialysate was sampled for the next 70 min, analogue to the standard microdialysis experiments.

\section{Measurement of interstitial fluid pressure $\left(\boldsymbol{P}_{\text {if }}\right)$}

$P_{\text {if }}$ was measured using the wick-in-needle (WIN) technique $[7,24]$. Briefly, a standard 23-gauge needle, with a 2$4 \mathrm{~mm}$ long sidehole, filled with nylon floss and saline was inserted into the central part of the tumor and connected to a transducer dome through a PE-50 catheter. The fluid communication between the interstitium and the measuring system was confirmed by compression and decompression of the catheter (clamping). This caused a transient rise and fall in the pressure. A measurement was accepted when the pressure returned to pre-clamp value ( $\pm 1 \mathrm{mmHg})$.

\section{Determination of collagen content in the tumors}

Hydroxyproline (to estimate collagen content) was determined in acid hydrolysates of the tumor tissue by a colometric method adapted from Woessner et al. [25].

\section{Oxygen stress measured by Malondialdehyd (MDA)}

To evaluate oxidative stress on lipids and membranes (the status of oxidative damage) we measured the lipid peroxidation product MDA, in controls and $\mathrm{HBO}$ treated tumors. MDA was analysed by a spectrophotometric assay according to the manufacturer's protocol (Northwest Life Science Specialties, LCC, Vancouver). The level of thiobarbituric reactive substances (TBARS) was assessed in tissue homogenates $(10 \% \mathrm{w} / \mathrm{v}$ prepared from frozen samples). As recommended for complex samples, the $3^{\text {rd }}$-derivative spectra (400-700 nm) were obtained, and MDA levels were calculated based on the peak value around 510-520 $\mathrm{nm}$

\section{Volume calculations by the dilution principle}

Extracellular volume (ECV) and plasma volume (PV) in tumor and skin was measured by radioactively labelled isotopes using the dilution principle as previously described [26]. Total tissue water (TTW) was calculated as: (wet weight-dry weight)/(dry weight). Samples were dried at $50^{\circ} \mathrm{C}$ until constant weight. The distribution volumes for ${ }^{51} \mathrm{Cr}$-EDTA (Institute of Energy Technology, Kjeller, Norway) and 125 I-labeled human serum albumin (125I-

Table I: The experimental groups.

\begin{tabular}{lccccc}
\hline Experimental groups & Gas & Ambient pressure & $\mathbf{p O}_{2}$ & Number of exposures & Exposure time \\
\hline Control & air & 1 bar & 0.2 & - & - \\
Repeated HBO treatment & $\mathrm{O}_{2}$ & $2 \mathrm{bar}$ & 2.0 & 4 & $90 \mathrm{~min}$ \\
Single HBO treatment & $\mathrm{O}_{2}$ & $2 \mathrm{bar}$ & 2.0 & $\mathrm{I}$ & $90 \mathrm{~min}$ \\
\hline
\end{tabular}


HSA) (Institute of Energy Technology, Kjeller, Norway), measuring ECV and PV respectively, were calculated as plasma equivalent volumes, i.e. counts per min per mg of tissue divided by counts per min per ml of plasma. Both isotopes were given after functional nephrectomy by bilateral ligation of the renal pedicles via flank incision. ${ }^{51} \mathrm{Cr}-$ EDTA (0.7 MBq) was injected into the jugular catheter and left to circulate for $85 \mathrm{~min}$ before injecting $0.05 \mathrm{MBq}$ ${ }^{125}$ I-HSA. Blood samples were taken 5 min later, by heart puncture.

\section{Immunohistochemistry}

The animals were sacrificed with saturated $\mathrm{KCl}$ during anaesthesia and the tumors were immediately dissected out and put into liquid $\mathrm{N}_{2}$ and then stored in $-80^{\circ} \mathrm{C}$.

Frozen tumor sections $(20 \mu \mathrm{m})$ were used for studying lymph-vessel morphology. The sections were stained with an antibody against lymphatic vessel endothelial hyaluronan receptor-1 (LYVE-1) with the Avidin-Biotin Complex (ABC) method, using a commercially available kit (Vector Vectastatin Elite ABC Staining Kit, Vector Laboratories Inc). Diaminobenzidine (DAB) was used as a chromogen to visualize the lymph-vessels. Finally, the sections were counterstained with Richardsons dye. The sections were examined using a Nikon light microscope (THP Eclipse E600, Nikon Corporation, Tokyo, Japan) and the images were captured with a Nikon Digital Camera (DXM 1200F, Nikon Corporation, Tokyo, Japan).

\section{Statistics}

All data were tested for normality prior to the choice of statistical analysis. Results were analysed statistically using two-way analysis with unpaired t-test comparing results from the groups. Paired t-test was used when comparing results within the same group of animals. Non-parametric Mann-Whitney test was used for the $P_{\text {if }}$ measurements, while ANOVA with Tukey post test was used to compare the results from the microdialysis. A value of $p<0.05$ was considered statistically significant.

\section{Results}

Dose response of $5 \mathrm{FU}$

To examine if different doses of the chemotherapeutic drug might influence the effect on tumor growth, dose response of 3 different doses were tested. However, there was no significant difference in tumor growth inhibition between the three different doses of 5FU (Figure 1). $(\mathrm{n}=$ 5 for each group).

\section{Uptake of [ $\left.{ }^{3} \mathrm{H}\right]-5 \mathrm{FU}$}

Microdialysis was used to examine if oxygenation of the tumor after HBO treatment influenced the direct uptake of the chemotherapeutic drug into the tumor tissue. Microdialysis showed no increase in uptake of $\left[{ }^{3} \mathrm{H}\right]-5 \mathrm{FU}$ into the tumor tissue 24 hours after the last repeated HBO treatment $(\mathrm{n}=8)$ compared to control $(\mathrm{n}=7)$. However, immediately after the single HBO treatment $(n=5)$ there was a significant increase in uptake $(\mathrm{p}<0.05)$ (Table 2$)$.

\section{Hyperoxia lowers interstitial fluid pressure $\left(\boldsymbol{P}_{i f}\right)$}

As elevated $P_{\text {if }}$ has been proposed to inhibit the transport and effect of chemotherapy, we wanted to elucidate if this was the case also for DMBA induced mammary tumors. The $P_{\text {if }}$ is usually high in solid tumors, reaching $5.5 \pm 0.9$ $\mathrm{mmHg}$ in the control tumors $(\mathrm{n}=9)$ (Table 2). However, the average $P_{\text {if }}$ after both single $(n=17)$ and repeated HBO $(\mathrm{n}=13)$ treatment was significantly reduced $(\mathrm{p}<$ 0.05) compared to control.

\section{Hyperoxia influences collagen fibrils}

A dense collagen network has been proposed to hinder efficient transport of chemotherapeutic drugs. Therefore we have elucidated collagen content in both control and HBO treated tumors. The amount of hydroxyproline was significantly lower in the HBO treated tumors compared to controls, indicating a corresponding decrease in collagen content (Table 2).

\section{Hyperoxia and oxygen radicals}

As hyperoxia might induce elevated oxygen radical levels, it was desirable to measure if this could have influenced the effect of chemotherapy after HBO treatment. Measurements of MDA-levels showed no significant differences in oxygen radicals compared to control $(n=5)$, neither in the acute $(n=5)$ nor the repeated $(n=5)$ HBO treated group (Table 2). The higher mean value in the repeated group is due to one diverging value. Discarding this value would give an identical mean as to the two other groups.

\section{Extracellular fluid volume, plasma volume and total tissue water}

Since $P_{\text {if }}$ in the HBO treated tumors was lowered, we assumed that this could influence the fluid distribution. However, there was no statistically significant difference in ECV, PV or TTW in either the tumor or skin tissue between control $(\mathrm{n}=9)$ and repeated HBO treated rats $(\mathrm{n}$ = 8) (Table 3).

\section{Hyperoxia influenced tumor lymphatics}

As the amount and functionality of lymph vessels influence both $\mathrm{P}_{\mathrm{i} f}$ fluid distribution and possibly the transport of chemotherapy, we stained lymph vessels to elucidate possible changes after HBO. Staining with LYVE-1 showed continuous lymphatic vessels in the mammary control tumors, located in the connective tissue close to larger blood vessels. After HBO treatment, however, the lymphatic vessels are disintegrated and no longer continuous (Figure 2). 


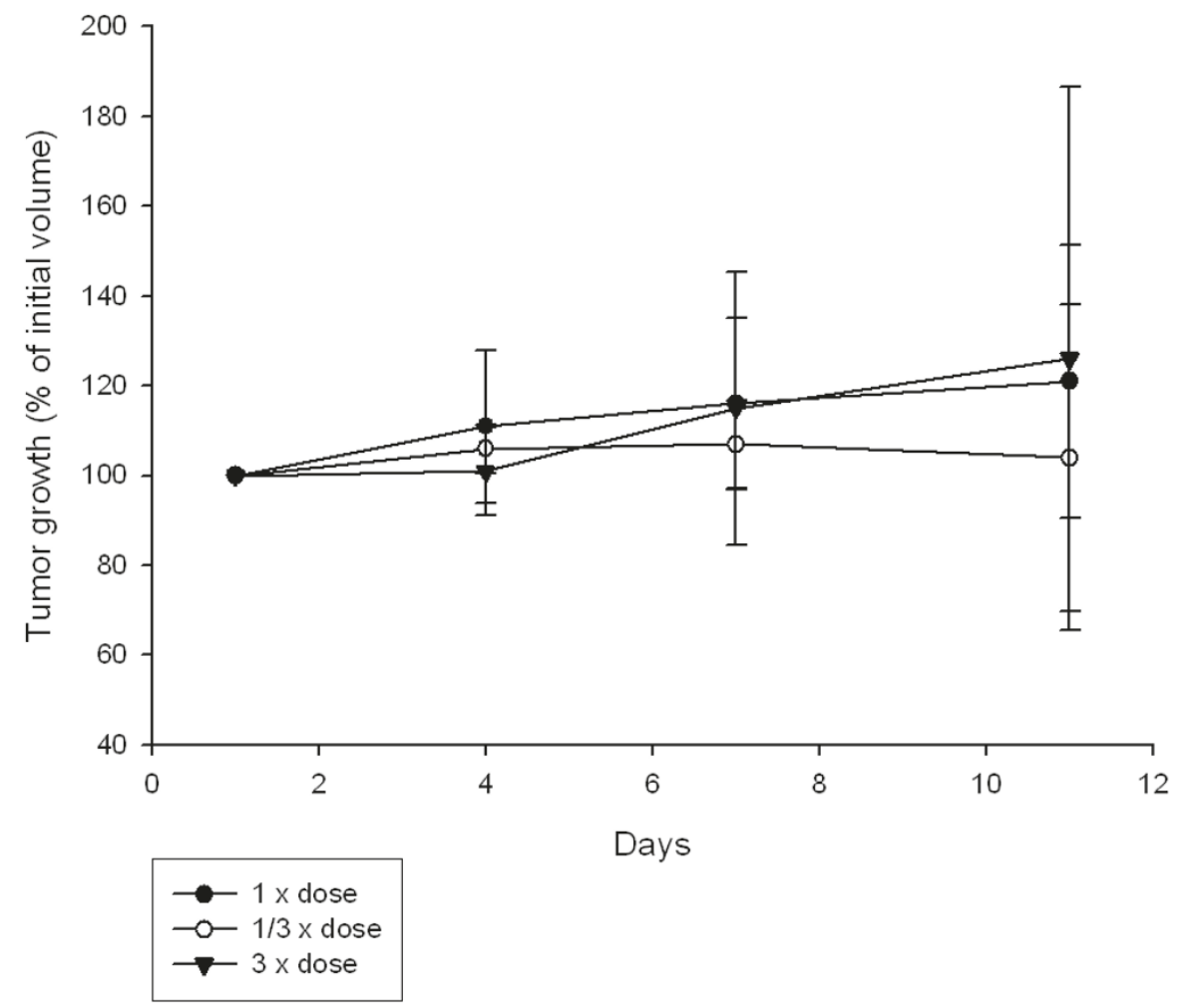

Figure I

The effect of three different doses of 5-fluorouracil (5FU) on tumor growth, original dose (I.5 mg/kg), I/3 (0.5 $\mathbf{m g} / \mathbf{k g})$ dose and $3 \times(4.5 \mathbf{~ m g} / \mathbf{k g})$ dose. Tumor growth is measured as \% of initial volume. Mean \pm SD.

\section{Discussion}

Stuhr et al. [14] demonstrated increased effect of the commonly used cytostatic drug 5FU in DMBA-induced mammary tumors, when injected intraperitoneally immediately before each HBO treatment. Dose-response experiments in this study showed no statistical difference between $1 / 3 \times, 1 \times$ and $3 \times$ dose of $5 F U$ (Figure 1 ), indicating that it must be the HBO treatment that potentiated the effect of the chemotherapeutic drug. We therefore wanted to investigate if there is an effect of either a single or repeated treatment of 2 bar pure oxygen on the uptake of radioactively labelled 5FU in the tumor tissue per se. We have concluded that the potentiation of the chemotherapeutic effect after HBO is not only due to an enhanced cytotoxicity of the tumor cells, as has been previously postulated in the literature $[15,27,28]$, but also due to an direct increase in uptake of the chemotherapeutic drug.

Successful delivery of systemically administered cytostatic agents to the tumor tissue requires that the drug must reach the target cells in optimal dosage and in addition be effective in the tumor microenvironment. After a molecule has been moved out of the blood vessels and into the interstitium, further transport is heavily influenced by the organization and conductivity, and thereby the composition of the interstitium. Several investigators have shown increased uptake of cytostatic agents after decreased tumor $P_{\text {if }}[8,29-32]$. In a recent review, Heldin et al. [8] suggest that increased $\mathrm{P}_{\mathrm{if}}$ contributes to a decreased capillary transport in tumors, to hinder efficient uptake of drugs into the tumor tissue. Additionally, the composition and organisation of the ECM, cell-cell interactions, and the tumor structure also affect drug penetration [33]. Eikenes et al. [11] proposed that the structure of the ECM is the single most important factor for macromolecule uptake. In accordance with this, Netti et al. [9], found an unexpected correspondence between transport resistance and the mechanical stiffness of the ECM, with an extended collagen network in the more penetration-resistant tumors. Also, others have shown that tumors with high collagen density and small interstitial space have lower drug penetration [34,35]. Furthermore, increased blood flow and blood vessel permeability are factors that are important in drug-uptake [36]. Thus, we chose especially to investigate the relation between uptake of the 
Table 2: Uptake of $\left[{ }^{3} \mathrm{H}\right]-5$-fluorouracil (5FU), interstitial fluid pressure $\left(P_{\text {if }}\right)$, collagen content and malondialdehyd (MDA) levels in controls and after repeated or single hyperbaric oxygen exposure (HBO).

\begin{tabular}{llll}
\hline & Control & Repeated HBO & Single HBO \\
\hline $\begin{array}{l}\left.\text { Uptake of [ }{ }^{3} \mathrm{H}\right]-5 F U \\
\text { (AUC tumor/AUC plasma) }\end{array}$ & $\begin{array}{l}0.17 \pm 0.12 \\
(\mathrm{n}=7)\end{array}$ & $\begin{array}{l}0.20 \pm 0.11 \\
(\mathrm{n}=8)\end{array}$ & $\begin{array}{l}0.42 \pm 0.21^{*} \\
(\mathrm{n}=5)\end{array}$ \\
$\mathbf{P}_{\text {if }}$ & $5.5 \pm 2.6$ & $2.3 \pm 2.7^{*}$ & $2.5 \pm 2.9^{*}$ \\
$(\mathrm{mmHg})$ & $(\mathrm{n}=9)$ & $(\mathrm{n}=11)$ & $17)$ \\
$\%$ \%collagen of dry weight & $11.6 \pm 5.0$ & $5.0 \pm 1.1^{*}$ & $(\mathrm{n}=4)$ \\
MDA levels & $(\mathrm{n}=6)$ & $0.15 \pm 0.11$ & $0.09 \pm 0.02$ \\
$(\mathrm{nmol} / \mathrm{mg}$ prot) & $0.09 \pm 0.01$ & $(\mathrm{n}=5)$ & $5)$ \\
\hline
\end{tabular}

Mean \pm SD.

$* \mathrm{p}<0.05$ vs control

cytostatic drug, transendothelial transport, tumor $\mathrm{P}_{\text {if }}$ and the collagen fibril network.

We found a significant reduction in tumor $\mathrm{P}_{\text {if }}$ after both acute and repeated HBO treatment, and expected that this would be reflected in an increased uptake of $\left[{ }^{3} \mathrm{H}\right]-5 \mathrm{FU}$ after both treatments. This is, however, not the fact in our study, where the uptake of $\left[{ }^{3} \mathrm{H}\right]-5 \mathrm{FU}$ was significantly increased after single HBO treatment, but not after the repeated HBO treatment. The cpm-ratio between tumor and plasma was stable over the 70 min sampling-period during microdialysis for the single HBO treatment, indicating a constant condition determining the uptake. The increased uptake of the drug into the tumor tissue, after single $\mathrm{HBO}$ exposure is most likely influenced by increased $\mathrm{pO}_{2}$. Previous studies reported enhanced $\mathrm{pO}_{2}$ for up to one hour after HBO treatment [12,37]. Since the repeated HBO treated animals were measured 24 hours after the last $\mathrm{HBO}$ treatment, the $\mathrm{pO}_{2}$ is normalized and any effect of $\mathrm{pO}_{2}$ will not be measurable. In the single $\mathrm{HBO}$ experiments, however, the $\mathrm{pO}_{2}$ is still high. The repeated $\mathrm{HBO}$ treatment probably induces more longterm changes in the tumor tissue that influences $P_{\text {if. }}$ The reduction in collagen may be involved in the reduction of $P_{\text {if }}$ over time. Stromal fibroblasts are able to exert tension on the collagen microfibrillar network through the collagen binding integrins [38]. When the amount of collagen fibrils is reduced, as shown with hydroxyproline quantification, this effect would not be as pronounced, and the $\mathrm{P}_{\text {if }}$ might be reduced. Thus, it seems like repeated HBO treatment have reduced tumor $P_{\text {if }}$ by reducing collagen content and density, most likely by enhancing breakdown of collagen.

Tumor vessels are hyperpermeable due to up-regulation of vascular mediators such as nitric oxide, bradykinin as well as anatomic defects like large gap junctions between adjacent cells and lack of pericytes [36,39]. An explanation for the lack of uptake of $\left[{ }^{3} \mathrm{H}\right]-5 \mathrm{FU}$ in the repeated $\mathrm{HBO}$ treated tumors, might be the proposed mechanism by Lee et al. [40] of "normalization" of the abnormal structure and function of the tumor vasculature after anti-angiogenic treatment. We have previously shown that repeated $\mathrm{HBO}$ induces an anti-angiogenic effect in the DMBA induced tumors [19,21]. Lee et al. [40] suggested that it is the quality of the vascular organization and not just the quantity of the vessels that determines the vessel function, and that the loss of endothelial cells would reduce the tortuousity of vessels or eliminate them altogether. Later, several preclinical and clinical studies $[41,42]$ have shown that the "normalized" vasculature after anti-angiogenic therapy had less leaky and tortuous vessels, with more normal basement membranes and better pericyte coverage, and that these structural changes

Table 3: The extracellular volume (ECV), plasma volume (PV) and total tissue water (TTW) in skin and tumor in control and after repeated hyperbaric oxygen (HBO) exposure.

\begin{tabular}{|c|c|c|c|c|c|c|}
\hline & \multicolumn{2}{|c|}{$\begin{array}{l}\text { ECV } \\
\text { (ml/g dry weight) }\end{array}$} & \multicolumn{2}{|c|}{$\begin{array}{l}\text { PV } \\
\text { (ml/g dry weight) }\end{array}$} & \multicolumn{2}{|c|}{$\begin{array}{l}\text { TTW } \\
\text { (ml/g dry weight) }\end{array}$} \\
\hline & Skin & Tumor & Skin & Tumor & Skin & Tumor \\
\hline $\begin{array}{l}\text { Control } \\
(n=9)\end{array}$ & $0.55 \pm 0.12$ & $1.00 \pm 0.27$ & $0.007 \pm 0.004$ & $0.07 \pm 0.04$ & $1.44 \pm 0.09$ & $3.73 \pm 0.45$ \\
\hline $\begin{array}{l}\text { HBO } \\
(n=8)\end{array}$ & $0.50 \pm 0.18$ & $0.85 \pm 0.47$ & $0.004 \pm 0.003$ & $0.06 \pm 0.03$ & $1.45 \pm 0.2$ & $4.05 \pm 0.9$ \\
\hline
\end{tabular}



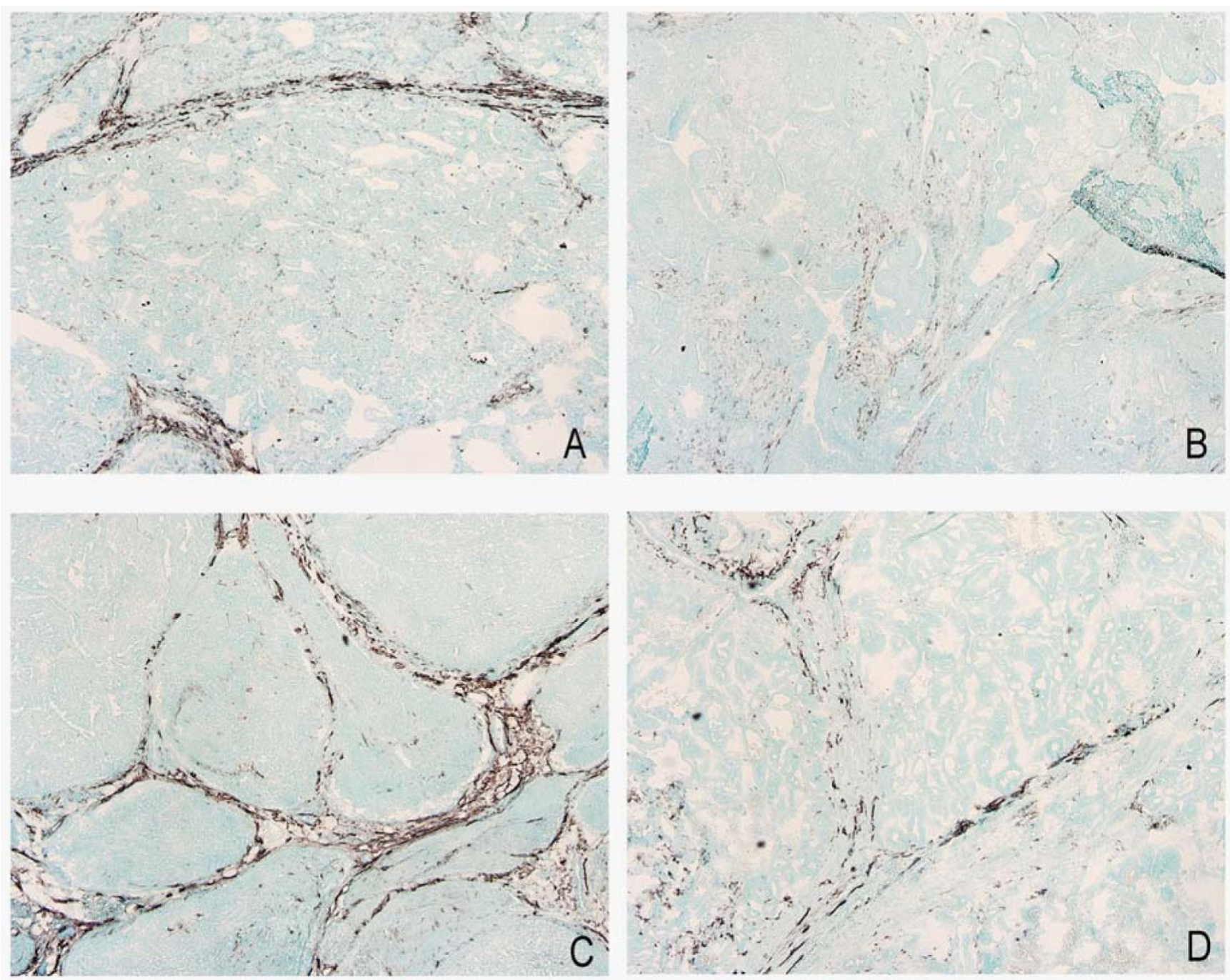

\section{Figure 2}

Lymph vessels stained with LYVE-I in two different control tumors (A and C) and hyperbaric oxygen (HBO) treated tumors (B and D). The staining was performed concomitant in the two groups. Note disintegration of lymphatics after $\mathrm{HBO}$ treatment, and seemingly anatomically normal lymphatics in untreated control tumors.

were accompanied by "normalization" of the tumor microenvironment. This modification in vascular architecture would decrease vascular permeability and reduce flow resistance and hence lower both mean venous pressure and $\mathrm{P}_{\text {if }}[8]$. Experimental studies have demonstrated that anti-angiogenic therapy can decrease the overall distribution of large macromolecules such as antibodies for instance $[43,44]$ and decrease blood perfusion [45]. Thus, since we have previously shown that HBO has an antiangiogenic effect on DMBA induced tumors after repeated HBO treatment [19], this will together with a possible reduced capillary permeability, impede transendothelial transport of $\left[{ }^{3} \mathrm{H}\right]-5 \mathrm{FU}$, even though $\mathrm{P}_{\text {if }}$ is lowered.
In normal tissue, the interstitial fluid volume is kept fairly constant by several mechanisms [46], such as lymph flow and adjustment of pressures acting across the capillary wall [47]. LYVE-1 surprisingly shows continuous lymph vessels in our control tumors, but dissolved lymph vessels after repeated HBO treatment. However, Fukumura et al. [48] stated that even though the structures with lymphatic endothelial marker are present in tumors, they probably do not transport fluid or macromolecules. This, together with the observed lowering of tumor $P_{\text {if }}$ after repeated HBO treatment, should lead to an increase in ECV. Nevertheless, ECV, PV and TTW did not change in tumors after repeated $\mathrm{HBO}$ treatment compared to control, indicating that neither the lowered $\mathrm{P}_{\text {if }}$ nor the disintegrated lymphatics after HBO contribute to the unchanged ECV found in 
the present study. As already mentioned, the possible "normalization" of the tumor vasculature, after repeated $\mathrm{HBO}$ treatment, is expected to normalize capillary permeability, and thereby prevent any increase in ECV, even though $\mathrm{P}_{\text {if }}$ is decreased.

Reactive oxygen species and oxidative stress are considered to be important in several aspects of malignancies, both in tumor development as well as therapeutic strategies such as radiotherapy [49]. Since changes in oxygen concentration may affect the production of its reactive derivatives in the tumor, it is relevant to suggest that antitumor effects of HBO may be due to oxidative stress. Furthermore, as stated in the introduction, some chemotherapeutic drugs require oxygen to generate free radicals that induce cytotoxicity. However, our measurements of lipid peroixidation (MDA) did not indicate any significant effect on the oxidative status of the tumor tissue. Oxidative stress is therefore not likely to be involved in the potentiated effect of 5FU after HBO.

Most solid tumors depend on increased rates of glycolysis to satisfy their energy demand [50]. This leads to decreased $\mathrm{pH}$ in the tumor microenvironment due to excessive lactate secretion. Hyperoxic treatment enhances oxygenation of the tumor tissue, and may therefore promote a reversion from the anaerobic metabolism back to non-tumorigentic, oxidative metabolism and thereby increased $\mathrm{pH}$ [21]. A less acidic microenvironment may therefore have a positive effect on the cytotoxicity of chemotherapy. However, although increased cytotoxicity has previously been postulated to be the main determinant of the enhanced effect of chemotherapy after HBO treatment in addition to enhanced neovascularisation, the present study has shown that it is also due to an active uptake of the drug into the tumor tissue.

In conclusion, we showed that hyperoxia increases the uptake of $\left[{ }^{3} \mathrm{H}\right]-5 \mathrm{FU}$ in DMBA-induced mammary tumors, independently of changes in $\mathrm{P}_{\text {if }}$, collagen fibril density, or transendothelial transport alone, as one could expect from the literature. The mechanism by which such an uptake occurs is clearly stimulated by elevated $\mathrm{pO}_{2}$, but still not elucidated.

\section{Competing interests}

The authors declare that they have no competing interests.

\section{Authors' contributions}

IM carried out the HBO treatments, the microdialysis, the $\mathrm{P}_{\text {if }}$ measurements, the volume experiments and the LYVE staining, in addition to drafting the manuscript. KJT performed the MDA experiments. OK carried out the hydroxyproline measurements. GS performed the dose response experiments and assisted on the microdialysis and vol- ume experiments. RKR and LS participated in the study design, interpretation of data and manuscript drafting. All authors read and approved the final manuscript.

\section{Acknowledgements}

This study was supported by grants from Helse Vest (Grants 9 I I 370), Edel and Ole Stakvold's foundation and The Norwegian cancer society. Ingrid Strand and Åse Rye Eriksen are gratefully acknowledged for technical assistance.

\section{References}

I. Hoogsteen IJ, Marres HA, Kogel AJ van der, Kaanders JH: The hypoxic tumour microenvironment, patient selection and hypoxia-modifying treatments. Clin Oncol (R Coll Radiol) 2007, I9(6):385-396.

2. Harrison L, Blackwell K: Hypoxia and anemia:factors in decreased sensitivity to radiation therapy and chemotherapy? Oncologist 2004, 9(Suppl 5):3I-40.

3. Jain RK: Transport of molecules in the tumor interstitium: a review. Cancer Research 1987, 47( ( 2):3039-305I.

4. Less JR, Posner MC, Boucher Y, Borochovitz D, Wolmark N, Jain RK: Interstitial hypertension in human breast and colorectal tumors. Cancer Research 1992, 52:6371-6374.

5. Nathanson SD, Nelson L: Interstitial fluid pressure in breast cancer, benign breast conditions, and breast parenchyma. Ann Surg Oncol I994, I(4):333-338.

6. Gullino PM, Clark SH, Grantham FH: The interstitial fluid of solid tumors. Cancer Research 1964, 24:780-797.

7. Wiig H, Tveit E, Hultborn R, Reed RK, Weiss L: Interstitial fluid pressure in DMBA-induced rat mammary tumours. Scand J Clin Lab Invest 1982, 42(2): 159-164.

8. Heldin NE, Rubin K, Pietras K, Östman A: High interstitial fluid pressure-an obstacle in cancer therapy. Nat Rev 2004, 4:806-8I3.

9. Netti PA, Berk DA, Swartz MA, Grodzinsky AJ, Jain RK: Role of extracellular matrix assembly in interstitial transport in solid tumors. Cancer Research 2000, 60:2497-2503.

10. Znati CA, Rosenstein M, McKee TD, Brown E, Turner D, Bloomer WD, Watkins S, Jain RK, Boucher Y: Irradiation reduces interstitial fluid transport and increases the collagen content in tumors. Clin Cancer Research 2003, 9:5508-55I3.

II. Eikenes L, Bruland ØS, Brekken C, de Lange Davies C: Collagenase increases the transcapillary pressure gradient and improves the uptake and distribution of monoclonal antibodies in human osteosarcoma xenografts. Caner Research 2004, 64:4768-4773.

12. Kinoshita Y, Kohshi K, Kunugita N, Tosaki T, Yokota A: Preservation of tumor oxygen after hyperbaric oxygenation monotored by magnetic resonance imaging. Brit J of Cancer 2000, 82:88-92.

13. Takiguchi N, Saito N, Nunomura M, Kouda K, Oda K, Furuyama N, Nakajima N: Use of 5-FU plus hyperbaric oxygen for treating malignant tumors: evaluation of antitumor effect and measurement of 5-FU in induvidual organs. Cancer Chemother Pharmacol 200I, 47(I): II-I4.

14. Stuhr LE, Iversen VV, Straume O, Maehle BO, Reed RK: Hyperbaric oxygen alone or combined with 5-FU attenuates growth of DMBA-induced rat mammary tumors. Cancer Lett 2004, 2 10(I):35-40.

15. Al-Waili NS, Betler G, Beale J, Hamilton RW, Lee BY, Lucas P: Hyperbaric oxygen and malignancies: a potential role in radiotherapy, chemotherapy, tumor surgery and phototherapy. Med Sci Monit 2005, I I(9):RA279-289.

16. Petre PM, Baciewicz FA Jr, Tigan S, Spears JR: Hyperbaric oxygen as a chemotherapy adjuvant in the treatment of metastatic lung tumors in a rat model. J Thorac Cardiovasc Surg 2003, I 25(I):85-95. discussion 95

17. Teicher BA, Crawford JM, Holden SA, Cathcart KN: Effects of various oxygenation conditions on the enhancement by FluosolDA of melphalan antitumor activity. Cancer Res 1987, 47( (19):5036-504I.

18. Alagoz T, Buller RE, Anderson B, Terrell KL, Squatrito RC, Niemann $\mathrm{TH}$, Tatman DJ, Jebson P: Evaluation of hyperbaric oxygen as a 
chemosensitizer in the treatment of epithelial ovarian cancer in xenografts in mice. Cancer 1995, 75(9):23।3-2322.

19. Raa A, Stansberg C, Steen VM, Bjerkvig R, Reed RK, Stuhr L: Hyperoxia retards growth and induces apoptosis and loss of glands and blood vessels in DMBA-induced rat mammary tumors. BMC Cancer 2007, 7(I):

20. Stuhr LB, Raa A, Øyan AM, Kalland KH, Sakariassen PO, Petersen K, Bjerkvig R, Reed RK: Hyperoxia retards growth and induces apoptosis, changes in vascular density and gene expression in transplanted gliomas in nude rats. J Neurooncology 2007 85(2): $|9|-202$.

21. Moen I, Oyan AM, Kalland KH, Tronstad KJ, Akslen LA, Chekenya M, Sakariassen PO, Reed RK, Stuhr LE: Hyperoxic treatment induces mesenchymal-to-epithelial transition in a rat adenocarcinoma model. PLoS One 2009, 4(7):e638I.

22. Schmelz M, Luz O, Averbeck B, Bickel A: Plasma extravasation and neuropeptide release in human skin as measured by intradermal microdialysis. Neuroscience Letters 1997 , 230:117-120.

23. Iversen VV, Brønstad A, Gjerde E-AB, Reed RK: Continuous measurements of plasma protein extravasation with microdialysis after various infalmmatory challenges in rat and mouse skin. Am J Physiol Heart Circ Physiol 2004, 286:H 08-HII2.

24. Fadnes HO, Reed RK, Aukland K: Interstitial fluid pressure in rats measured with a modified wick technique. Microvascular Research 1977, |4(27):27-36.

25. Woessner JR: The determination of hydroxyproline in tissue and protein samples containing small proportions of this imino acid. Archives of biochemistry and biophysics 196I, 93:440-447.

26. Reed RK, Lepsøe S, Wiig H: Interstitial exclusion of albumin in rat dermis and subcutis in over- and dehydration. Am J Physiol 1989, 257:HI8I9-1827.

27. Kalns J, Krock L, Piepmeier E Jr: The effect of hyperbaric oxygen on growth and chemosensitivity of metastatic prostate cancer. Anticancer Res 1998, I8(IA):363-367.

28. Daruwalla J, Christophi C: Hyperbaric oxygen therapy for malignancy: A review. World Journal of Surgery 2006 30(I2):2II2-2|3|.

29. Emerich DF, Dean RL, Snodgrass $P$, Lafreniere D, Agostino M, Wiens T, Xiong H, Hasler B, Marsh J, Pink M, Kim BS, Perdomo B, Bartus RT: Bradykinin modulation of tumor vasculature: II. activation of nitric oxide and phospholipase A2/prostaglandin signaling pathways synergistically modifies vascular physiology and morphology to enhance delivery of chemotherapeutic agents to tumors. J Pharmacol Exp Ther 200I, 296(2):632-64I.

30. Pietras K, Rubin K, Sjoblom T, Buchdunger E, Sjoquist M, Heldin CH, Ostman A: Inhibition of PDGF receptor signaling in tumor stroma enhances antitumor effect of chemotherapy. Cancer Research 2002, 62(19):5476-5484.

31. Salnikov AV, Iversen VV, Koisti M, Sundberg C, Johansson L, Stuhr LB, Sjoquist M, Ahlstrom H, Reed RK, Rubin K, Lammerts E, Roswall P, Gotwals PJ, Koteliansky VE, Heldin NE: Lowering of tumor interstitial fluid pressure specifically augments efficacy of chemotherapy. Interference with TGF-betal and -beta3 in tumor stroma lowers tumor interstitial fluid pressure independently of growth in experimental carcinoma. Faseb J 2003, I7(12): I756-1758.

32. Stuhr LEB, Salnikov AV, Iversen VV, Salvesen G, Rubin K, Reed RK High-dose, short-term, anti-inflammatory treatment with dexamethasone reduces growth and augments the effects of 5-fluorouracil on dimethyl-alpha-benzanthracene-induced mammary tumors in rats. Scand I Clin Lab Invest 2006, 66:477-486

33. Davies E, Clarke C, Hopkins A: Malignant cerebral glioma-I: Survival, disability, and morbidity after radiotherapy. BMJ 1996 , 313:1507-15I2.

34. Kuh $\mathrm{H}$, Jang SH, Wienties MG, Weaver JR, Au JL: Determinants of paclitaxel penetration and accumulation in human solid tumor. J Pharmacol Exp Ther 1999, 290(2):87|-880.

35. $\mathrm{Au} \mathrm{J}$, Jang SH, Wientjes MG: Clinical aspects of drug delivery to tumors. J Control Release 2002, 78(I-3):8I-95.

36. Jain RK: Delivery of molecular and cellular medicine to solid tumors. J Cont Release 1998, 53( I-3):49-67.

37. Brizel DM, Lin S, Johnson JL, Brooks J, Dewhirst MW, Piantadosi CA: The mechanisms by which hyperbaric oxygen and carbogen improve tumor oxygenation. Brit I of Cancer 1995, 72(5): I I20-II 24.

38. Reed RK, Berg A, Gjerde EA, Rubin K: Control of interstitial fluid pressure: role of betal-integrins. Semin Nephrol 200I, 21(3):222-230.

39. Jain RK: Normalizing tumor vasculature with anti-angiogenic therapy: A new paradigm for combination therapy. Nat Med 200I, 7(9):987-989.

40. Lee C-G, Heijn M, di Tomaso E, Griffon-Etienne G, Ancukiewich M, Koike C, Park KR, Ferrara N, Jain RK, Suit HD, Boucher Y: Anti-Vascular Endothelial Growth Factor treatment augments tumor radiation responce under normoxic or hypoxic conditions. Cancer Research 2000, 60:5565-5570.

4I. Jain RK, Tong RT, Munn LL: Effect of vascular normalization by antiangiogenetic therapy on interstitial hypertension, peritumor edema, lymphatic metastasis: insights from a mathematical model. Cancer Research 2007, 67(6):2729-2735.

42. Tong RT, Boucher Y, Kozin SV, Winkler F, Hicklin DJ, Jain RK: Vascular normalization by vascular endothelial growth factor receptor 2 blockade induces a pressure gradient across the vasculature and improves drug penetration in tumors. Cancer Research 2004, I(64):373 I-3736.

43. Weis SM, Cheresh DA: Pathophysiological consequences of VEGF-induced vascular permeability. Nature 2005, 437(7058):497-504.

44. Nakahara T, Norberg SM, Shalinsky DR, Hu-Lowe DD, McDonald DM: Effect of inhibition of vascular endothelial growth factor signaling on distribution of extravasated antibodies in tumors. Cancer Res 2006, 66(3): | 1434- 4445

45. Willett CG, Kozin SV, Duda DG, di Tomaso E, Kozak KR, Boucher Y, Jain RK: Combined Vascular Endothelial Growth Factor-targeted therapy and radiotherapy for rectal cancer: Theory and clinical practice. Seminars in oncology 2006, 33:S35-S40.

46. Aukland K, Reed RK: Interstitial-lymphatic mechanisms in the control of extracellular fluid volume. The American physiological society 1993, 73(I): I-78.

47. Wiig H, Rubin K, Reed RK, Tveit E, Hultborn R, Weiss L: New and active role of the interstitium in control of interstitial fluid pressure: potential therapeutic consequences. Evaluation of methodologies for measurement of interstitial fluid pressure (Pif): physiological implications of recent $\mathrm{Pi}$ data. Interstitial fluid pressure in DMBA-induced rat mammary tumours. Acta Anaesthesiol Scand 2003, 47(2): I I I- I2 I.

48. Fukumura $D$, Jain RK: Tumor microvasculature and microenvironment: Targets for anti-angiogenesis and normalization. Microvascular Research 2007 in press. Article

49. Halliwell $B$ : Oxidative stress and cancer: have we moved forward? Biochem J 2007, 40 I ( I): I- I I.

50. Gatenby RA, Gillies RJ: Why do cancers have high aerobic glycolysis? Nat Rev Cancer 2004, 4( I I):89I-899.

\section{Pre-publication history}

The pre-publication history for this paper can be accessed here:

http://www.biomedcentral.com/1471-2407/9/446/pre pub 